\title{
ON THE INFLUENCE OF EXERCISE ON THE GROWTH OF ORGANS IN THE ALBINO RAT
}

\author{
SHINKISHI HATAI \\ The Wistar Institute of Anatomy and Biology, Philadelphia
}

For the past three years experiments have been carried on to determine the effect of long-continued exercise on the growth of organs in the albino rat. The main object of the present investigation was twofold: (1) to repeat the observations of Donaldson ('11) who found a slight increase (2.6 per cent) in the brain weight in albino rats which had been subjected to exercise for the period of six months, and (2) to extend the observations to other organs besides the central nervous system. The present paper includes the data obtained by the previous study, just mentioned, as well as the results of my own investigations.

\section{TECHNIQUE}

The opportunity for exercise was given by placing the test rats in a form of eage which was used by Slonaker ('08) in his studies on the daily activity of the albino rat. The revolving cage consists of a large cylindrical drum 58.5 inches in circumference, made of $\frac{3}{16}$-inch wire mesh, which revolves on a stationary axle. On the axle was fastened the nest box and the food and water pans. The number of revolutions of the eage is registered by a cyclometer.

Albino rats one month old were placed in these cages for a period of three to six months, which is equivalent to seven to fourteen years of human life. Each cage contained a single rat. The rats used for the control were litter brothers and sisters of those in the revolving cages and were placed in the ordinary laboratory cages (one foot high, one foot wide and six feet long). The total number of rats examined was 36 controls 
and 42 test animals. For the material of the 1914 series the present writer is under great obligation to Miss Caroline Holt, a graduate student at The Wistar Institute, who permitted the use of her exercised rats with their controls, and I wish to thank her for her courtesy in this matter.

\section{METHOD OF COMPUTING THE AMOUNT OF ALTERATION}

In determining the deviations of the organs in the exercised rats from those in the controls, the following method was used: As a first step, the weights of the various organs corresponding to the observed body length of the rats were computed by means of formulas (for various formulas see Hatai ' 13 and '14). This computation was made for both the controls and the exercised rats. The differences between the observed and computed values of both control and exercised are now transformed into percentages by taking the computed values as 100 per cent. Thus we obtain two sets of percentage values, one expressing the difference between the computed and observed values in the control rats, and the other expressing the difference between computed and observed values in the exercised rats. If exercise has not altered the organs of the animals at all, then these two sets of percentages should be alike within the limits of the normal fluctuations. If, on the other hand, exercise has altered the organs, these two sets of percentages should differ more or less according to the nature of the response to exercise. If in the case of any organ we now take the difference between the percentage value obtained for the controls and that for the exercised rats, this difference represents the amount by which the exercised rats, as compared with controls, depart from the value obtained by the formula. By the use of this procedure, successive series are thus referred to the formula values in each instance and since the deviations are measured by this means always from the same standard, they may be directly compared with one another.

In the case of the thymus gland, the age of the rats was taken as the basis for the computation, since the weight of the thymus is much more highly correlated with the age than with either the 
weight or the length of the body (Hatai '14). The example taken from the 1911 male series (the second series in table 3), may serve to illustrate the method of comparison described above (table 1). Expressing in words the results as given in the last line of this table, these show that the exercised rats are 13.4 per cent heavier than the controls and have a tail 1.62 per cent longer.

\section{AMOUNT OF EXERCISE TAKEN}

The rats in the revolving cages often take a large amount of voluntary exercise. To illustrate this I have chosen an example from the 1912 series and given the average distance run during every 24 hours for the entire period of 93 days.

As will be seen from table 2 , the distance run is almost incredible in some instances, the greatest average run for 93 days being 10 miles per 24 hours; a record made by one female. Since the rat is most active during the night (Slonaker '12) this daily run

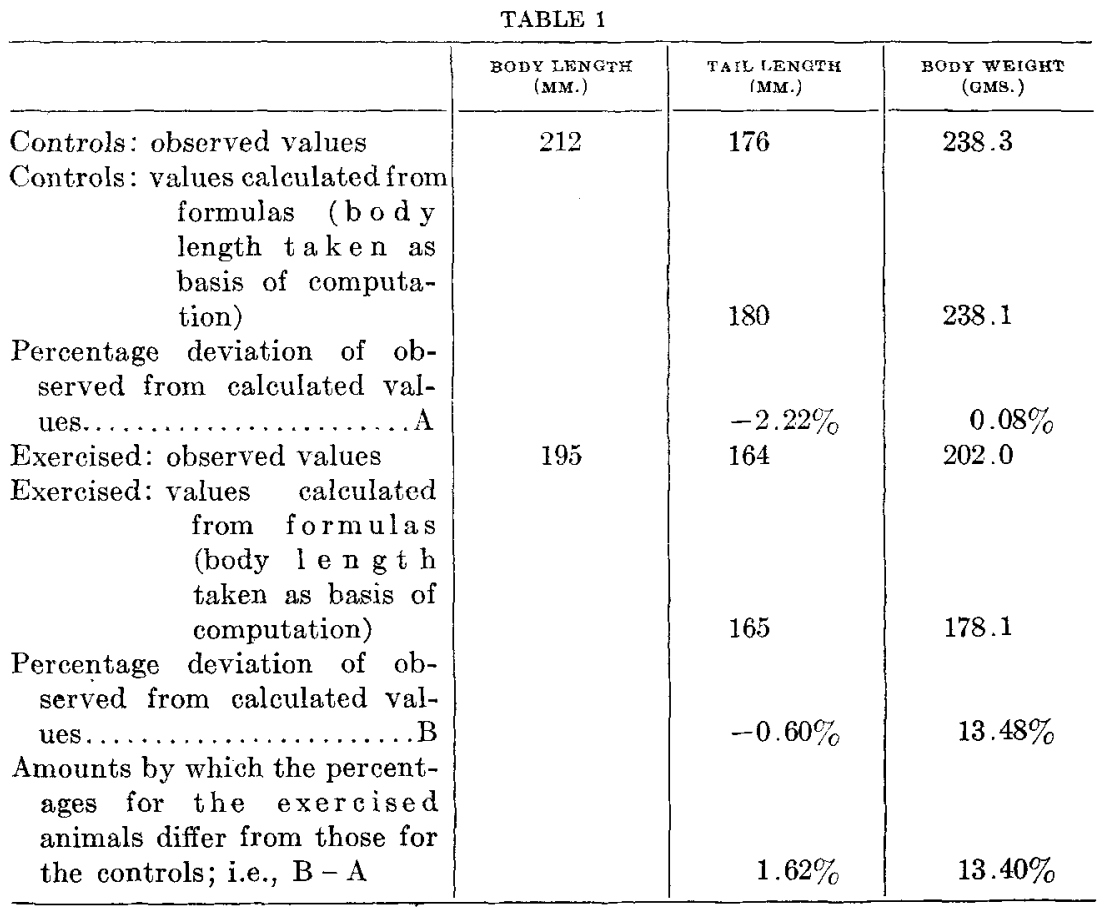


TABLE 2

Showing the distance run by the exercised rats in a period of 93 days

\begin{tabular}{c|c|c|c|c|c}
\hline $\begin{array}{c}\text { EXERCISED RAT, } \\
\text { No. }\end{array}$ & $\begin{array}{c}\text { NO. OF MILES } \\
\text { PER 24 HOURS }\end{array}$ & SEX & $\begin{array}{c}\text { EXERCISED RAT } \\
\text { NO. }\end{array}$ & $\begin{array}{c}\text { NO. OF MILES } \\
\text { PER 24 HOURS }\end{array}$ & SEX \\
\hline $8 \mathrm{~B}_{10}$ & 0.4 & M. & $7 \mathrm{~A}_{5}$ & 7.6 & $\mathrm{M}$. \\
$7 \mathrm{~A}_{47}$ & 0.5 & $\mathrm{M}$. & $7 \mathrm{~A}_{4}$ & 7.6 & $\mathrm{M}$. \\
$8 \mathrm{~B}_{9}$ & 0.6 & $\mathrm{M}$. & $7 \mathrm{~B}^{2}{ }_{17}$ & 6.2 & $\mathrm{~F}$. \\
$7 \mathrm{~B}^{2}{ }_{16}$ & 0.6 & $\mathrm{M}$. & $7 \mathrm{~B}_{20}$ & 7.4 & $\mathrm{~F}$. \\
$7 \mathrm{~B}_{19}$ & 4.8 & $\mathrm{M}$. & $6 \mathrm{~B}^{2}{ }_{92}$ & 7.7 & $\mathrm{~F}$. \\
$7 \mathrm{~B}_{48}$ & 6.5 & $\mathrm{M}$. & $6 \mathrm{~B}^{2}{ }_{83}$ & 8.3 & $\mathrm{~F}$. \\
$6 \mathrm{~B}^{2}{ }_{82}$ & 6.7 & $\mathrm{M}$. & $8 \mathrm{~B}_{11}$ & 10.2 & $\mathrm{~F}$. \\
\hline
\end{tabular}

was accomplished for the most part within a twelve-hour period. With the exception of the first four sluggish male rats, the average run was about $6 \frac{1}{2}$ miles for males and 8 miles for females. Slonaker found that female rats were more active than the males and he further noticed considerable individual variation in the activities. The present results agree nicely with the observations of Slonaker. It is interesting to note also that the maximum average run by Slonaker's rats was 11 miles (average for one month) while that of mine was 10 miles per day for 93 days, thus showing a close agreement even in this respect. We do not know how active the wild Norway rats may be, but a considerable curtailment of the normal activity in the albino rats under domestication seems highly probable.

The effects of long-continued exercise on the body of the Albino as a whole, and on the organs, was the object of the present investigation.

IAFLUENCE OF EXERCISE FOR 90 TO 180 DAYS ON THE EXTERNAL MEASUREMENTS AND ON THE ORGAN WEIGHTS

\section{Alterations of the external measurements}

The external measurements of the exercised albino rats contrasted with those of the controls are given in table 3.

To prevent misunderstanding or misinterpretation, a word of explanation touching the tables is in order. Using the series for 1911 males, the second one in table 3 (the same which has been used as an illustration for procedure on page 649), attention 
is called to the following points: The entries for the control are the observed values-the entries for the exercised are the observed values. The percentages deviations of both controls and exer-

TABLE 3

Showing the external measurements in both control and exercised rats

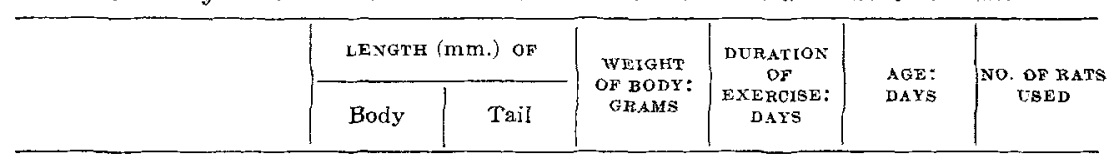

Stock albino rat (Donaldson, '11) $M$. and $F$.

\begin{tabular}{l|r|r|r|r|r|r}
\hline Control... ........ 199 & 165.00 & 199.60 & 180 & 242 & 31 \\
Exercised.......... & 195 & 163.00 & 192.80 & & 242 & 24 \\
Per cent: Exerc.-cont. & & 0.42 & 2.90 & & & \\
\hline
\end{tabular}

Stock albino rat, 1911 series $M$.

\begin{tabular}{l|r|r|r|r|r|r}
\hline Control........... & 212 & 176.00 & 238.30 & 180 & 215 & 21 \\
Exercised.......... & 195 & 164.00 & 202.00 & & 195 & 11 \\
Per cent: Exerc.-cont. & & 1.62 & 13.40 & & & \\
\hline
\end{tabular}

Inbred albino rat, 1912 series $M$.

\begin{tabular}{l|r|r|r|r|r|r}
\hline Control........... & 212 & 184.00 & 217.30 & 180 & 212 & 9 \\
Exercised.......... & 214 & 181.00 & 245.30 & & 213 & 10 \\
Per cent: Exere.cont. & & -2.77 & 8.42 & & & \\
\hline
\end{tabular}

Inbred albino rat, 1912 series $F$.

\begin{tabular}{l|r|r|r|r|r|r}
\hline Control......... & 191 & 174.00 & 155.40 & 180 & 215 & 6 \\
Exercised......... & 198 & 173.00 & 179.80 & & 213 & 7 \\
Per cent: Exerc.-cont. & & -4.77 & 2.52 & & & \\
\hline
\end{tabular}

Stock albino rat, 1914 series $M$.

\begin{tabular}{l|l|r|r|r|r|r}
\hline Control.......... & $176(\mathrm{~F})$ & 167.00 & 145.60 & 90 & 135 & 3 \\
Exercised. . ....... & 198 & 178.00 & 220.90 & & 135 & 4 \\
Per cent: Exerc.-cont. & & -2.56 & 11.35 & & & \\
\hline
\end{tabular}

Stock albino rat, 1914 series $F$.

\begin{tabular}{l|c|c|c|c|c|c}
\hline Control.......... 176 & 167.00 & 145.60 & 90 & 135 & 3 \\
Exercised......... 182 & 171.00 & 159.40 & & 135 & 4 \\
Per cent: Exerc.-cont. & -1.60 & -1.87 & & & \\
\hline $\begin{array}{l}\text { Percentage by which exercised } \\
\text { rats differ from controls. }\end{array}$ & & & & & \\
Same weight given to each \\
series................
\end{tabular}


cised from the formula values have been determined but are not entered in the table. The difference between these two percentage deviations is alone given in the table after '\%: exerc.contr.' To test the correctness of these last figures it is always necessary to carry out the operations which have been described (p. 648). This same explanation applies to the other series in this table and also to the other tables 3,4 and 5 .

Body length. The average absolute length of the body is practically identical in both the exercised and control rats. The difference amounts to 0.5 per cent in favor of the controls. The data given by Donaldson ('11) for a single series show also a small difference of 2 per cent in favor of the control. We may conclude therefore that exercise does not alter the growth of body in length to any noticeable extent.

Tail length. The tail length with respect to body length tends to be slightly shorter in the exercised than in the non-exercised rats. The average difference is 2.02 per cent in favor of the control. The data given by Donaldson show practical identity in his series. However, the difference is noted in four out of my five series and I conclude therefore that exercise tends to retard the growth of the tail in length.

Body weight. A slight increase of 6.76 per cent is given in the average body weight for the exercised rats when compared with that of the non-exercised. This difference appears in four series out of five. Data given by Donaldson shows also an increase of 2.90 per cent in favor of the exercised. This relative gain in body weight of the exercised rats may be due in part to the absence of lung disease in the exercised rats. As will be seen later, most of the control rats were suffering from a lung infection, while most of the exercised rats were free from this. It is therefore possible that the increased body weights shown in table 3 are in some measure due to the slightly emaciated condition of the control rats, thus raising the relative value in favor of the exercised rats. I am therefore inclined to believe that in the case of the albino rat the body weight is not much affected by the form of exercise here given-though it may be slightly increased. 
Considering these three external characters together, we may say that long-continued exercise does not modify significantly any of the characters here mentioned with the possible exception of the tail length, which shows a slight tendency to a deficit with respect to the body weight.

\section{Alterations of the viscera}

TABLE 4

Showing the weights of viscera of the exercised rats compared with those of the controls. Arrangement of data explained on p. 650.

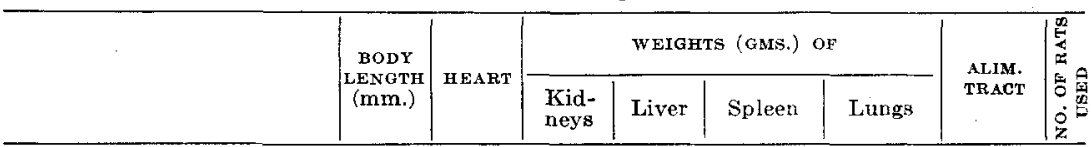

Stock albino rat, 1911 series, $M$.

\begin{tabular}{|c|c|c|c|c|c|c|c|}
\hline Control. & 212 & 0.886 & 1.768 & 10.21 & 0.611 & 1.796 & 21 \\
\hline Exercised. . & 195 & 0.904 & 1.867 & 10.35 & 0.589 & 1.588 & \\
\hline Per cent: Exerc--cont. & & 26.980 & 32.170 & 23.15 & 25.980 & 17.250 & \\
\hline
\end{tabular}

Inbred albino rat, 1912 series $M$.

\begin{tabular}{|c|c|c|c|c|c|c|c|c|}
\hline $\begin{array}{l}\text { Control... } \ldots \ldots \ldots \ldots \\
\text { Exercised.............. } \\
\text { Per cent: Exerc.-cont. }\end{array}$ & $\begin{array}{l}212 \\
214\end{array}$ & $\begin{array}{l}0.784 \\
0.874 \\
7.380\end{array}$ & \begin{tabular}{|r|}
1.627 \\
2.032 \\
17.300
\end{tabular} & $\begin{array}{r}8.50 \\
11.36 \\
22.46\end{array}$ & $\begin{array}{r}0.445 \\
0.415 \\
-6.790\end{array}$ & $\begin{array}{r}2.325 \\
1.228 \\
-82.990\end{array}$ & $\begin{array}{l}7.86 \\
9.15 \\
9.49\end{array}$ & \\
\hline \multicolumn{9}{|c|}{ Inbred albino rat, 1912 series $F$. } \\
\hline $\begin{array}{l}\text { Exercised............. } \\
\text { Per cent: Exerc.-cont. }\end{array}$ & $\begin{array}{l}191 \\
198\end{array}$ & $\left|\begin{array}{r}0.587 \\
0.787 \\
17.430\end{array}\right|$ & \begin{tabular}{|l|}
1.246 \\
1.530 \\
8.310
\end{tabular} & $\begin{array}{r}6.48 \\
8.85 \\
17.24\end{array}$ & $\begin{array}{r}0.395 \\
0.363 \\
-14.900\end{array}$ & $\begin{array}{r}2.205 \\
0.999 \\
-89.970\end{array}$ & $\begin{array}{l}6.77 \\
8.12 \\
7.52\end{array}$ & \\
\hline \multicolumn{9}{|c|}{ Stock albino rat, 1914 series $M$. } \\
\hline cont. & \begin{tabular}{|r|}
$(\mathrm{F}) 176$ \\
198
\end{tabular} & $\mid \begin{array}{r}0.595 \\
1.044 \\
37.680\end{array}$ & $\begin{array}{r}1.054 \\
1.790 \\
25.280\end{array} \mid$ & $\begin{array}{r}6.19 \\
9.06 \\
13.12\end{array}$ & $\begin{array}{r}0.651 \\
0.444 \\
-61.870 \\
\end{array}$ & $\begin{array}{r}1.000 \\
1.128 \\
-15.160 \\
\end{array}$ & $\left|\begin{array}{r}8.27 \\
8.82 \\
-14.80\end{array}\right|$ & \\
\hline \multicolumn{9}{|c|}{ Stock albino rat, 1914 series $F$. } \\
\hline $\begin{array}{l}\text { Exercised.............. } \\
\text { Per cent: Exere-cont. }\end{array}$ & $\begin{array}{l}176 \\
182\end{array}$ & $\mid \begin{array}{r}0.595 \\
0.822 \\
27.130\end{array}$ & $\left|\begin{array}{r}1.054 \\
1.317 \\
11.930\end{array}\right|$ & $\begin{array}{r}6.19 \\
7.74 \\
12.72\end{array}$ & $\begin{array}{r}0.651 \\
0.457 \\
-63.210\end{array}$ & $\begin{array}{l}1.000 \\
1.105 \\
1.390\end{array}$ & $\begin{array}{r}8.27 \\
8.09 \\
-9.76\end{array} \mid$ & \\
\hline $\begin{array}{l}\text { exercised albino rat } \\
\text { from controls. Same } \\
\text { given to each series. }\end{array}$ & fer & $|23.320|$ & 19.000 & 17.74 & -24.160 & $|-33.090|$ & $|-1.89|$ & \\
\hline
\end{tabular}


From table 4 we note the following modifications.

Heart. In all the series the weight of the heart is considerably heavier in the exercised rats than in the controls. The average difference is 23.32 per cent in favor of the exercised rat.

Kidneys. The kidneys of the exercised rats are also heavier than those of the controls in all the series. We note the average difference of 19 per cent in favor of the exercised.

Liver: The weight of the liver is also heavier in the exercised rat in all the series. The difference is $\mathbf{1 7 . 7 4}$ per cent in favor of the exercised rat.

Spleen. On the other hand, the weight of the spleen is greater in the control than in the exercised. The difference amounts to as much as 24.16 per cent in favor of the controls. This difference does not appear to be due to a greater variability of the spleen, since it occurs in four series out of five, and furthermore, the same phenomena occurs in another series, which will be considered later (table 7 ). The reason why exercise retards the normal growth of the spleen with respect to body length is not clear.

Lungs. We notice the average difference of minus 33.90 per cent in the exercised lungs compared with the controls. In the case of the lungs, however, those heavier than normal for the body weight are associated with a lung infection. As a matter of fact, most of the control rats were infected, while the exercised rats were free from infection. It has already been noted that the infection of the lungs in the control rats was probably responsible in part for the relatively small body weight of the controls. It is highly interesting to see that exercise prevents, or at least delays, an onset of a very prevalent pulmonary infection in the albino rat.

Alimentary tract. The alimentary tract as here designated includes not only the digestive tract proper, such as the stomach, intestine, etc., but also all attached structures, as the pancreas, omentum, as well as fat deposited in them. As is shown in table 4 , the alimentary tract is not evidently modified. We note an average difference of 1.89 per cent in favor of the controls. This small difference, associated as it is with the bal- 
anced distribution of plus and minus variations, justifies our conclusion that exercise has not affected this part of the visceral system.

\section{Alterations of ductless glands}

Testes. The testes of the exercised rats show an average increase of 12.33 per cent when contrasted with those of the controls. This increase occurs in both the male series, thus showing the significance of the reaction.

Ovaries. The ovaries in the exercised rats show an increase of 84.33 per cent when contrasted with those of the controls. The difference between the exercised and controls in these organs is evident even at a glance. It is interesting to note that the sex glands of the Norway rats are normally heavier than those of the Albinos. The increase here shown as the result of exercise may possibly indicate a return to the wild form, not in size alone but also in fertility.

Hypophysis. The hypophysis responds to exercise differently according to sex. We note an increase of 10.25 per cent in the case of the male and a deficit of 22.23 per cent in the case of the female. The approach of the weights in the two sexes and the larger loss in the female bring about relations which $I$ have observed in the wild Norway (Hatai '14 b).

Suprarenal glands. As in the case of the hypophysis, the suprarenal glands show also dissimilar reaction to exercise according to the sex. Thus we note practically no alteration in the male ( 0.84 per cent), while there is an increase of 47.76 per cent in the female--again relations such as the wild Norway shows (Hatai '14 b).

Thyroid. We note a difference of nearly 13.44 per cent in favor of the control rats.

Thymus gland. The thymus of the exercised rat shows a slight relative increase of 4.80 per cent when contrasted with that of the control. It occurs, however, in only two cases out of four, and furthermore the greater variability in the alteration suggests that the difference here noted may not be significant at all. We must await the results of future experiments to make any positive statement. 
TABLE 5

Showing the weights of the ductless glands in the exercised rats compared with those in the controls. Arrangement of data explained on page 650.

\begin{tabular}{|c|c|c|c|c|c|c|}
\hline & \multirow{2}{*}{ SEX GLANDS } & \multicolumn{4}{|c|}{ WEIGHTS (GMS.) of } & \multirow{2}{*}{$\begin{array}{c}\text { No. OF } \\
\text { RAS } \\
\text { USED }\end{array}$} \\
\hline & & Hypophysis & Suprarenals & Thyroid & Thymus & \\
\hline \multicolumn{7}{|c|}{ Stock albino rats, 1911 series $M$. } \\
\hline \begin{tabular}{l|r} 
Control..... & 212 \\
Exercised... & 195 \\
Per cent: Exerc.- \\
$\quad$ cont.
\end{tabular} & $\begin{array}{r}2.2280 \\
2.3380 \\
19.7800\end{array}$ & & & & & $\begin{array}{l}21 \\
11\end{array}$ \\
\hline \multicolumn{7}{|c|}{ Inbred albino rat, 1912 series $M$. } \\
\hline 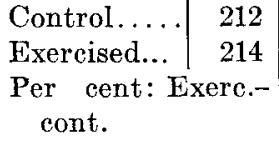 & $\begin{array}{l}2.3430 \\
2.5030 \\
4.8800\end{array}$ & $\begin{array}{r}0.0085 \\
0.0096 \\
10.2500\end{array}$ & $\begin{array}{l}0.0328 \\
0.0339 \\
0.8400\end{array}$ & $\begin{array}{l}0.0344 \\
0.0354 \\
0.2700\end{array}$ & $\begin{array}{l}0.0984 \\
0.1085 \\
7.1800\end{array}$ & $\begin{array}{r}9 \\
10\end{array}$ \\
\hline \multicolumn{7}{|c|}{ Inbred albino rat, 1912 series $F$. } \\
\hline \begin{tabular}{l|r} 
Control..... & 191 \\
Exercised... & 198 \\
Per cent: Exerc.- \\
cont.
\end{tabular} & $\begin{array}{r}0.0368 \\
0.0602 \\
46.4200\end{array}$ & $\begin{array}{r}0.0113 \\
0.0127 \\
-2.0200\end{array}$ & $\begin{array}{r}0.0425 \\
0.0622 \\
27.3200\end{array}$ & $\begin{array}{r}0.0273 \\
0.0282 \\
-5.4600\end{array}$ & $\begin{array}{r}0.1051 \\
0.1698 \\
41.7000\end{array}$ & $\begin{array}{l}6 \\
7\end{array}$ \\
\hline \multicolumn{7}{|c|}{ Stock albino rat, 1914 series $M$. } \\
\hline \begin{tabular}{l|l} 
Control..... & 176 \\
Exercised... & 198 \\
Per cent: Exerc.- \\
cont.
\end{tabular} & & . & & $\begin{array}{r}0.0282 \\
0.0290 \\
-25.8100\end{array}$ & $\begin{array}{r}0.1931 \\
0.1355 \\
-25.4900\end{array}$ & $\begin{array}{l}3 \\
4\end{array}$ \\
\hline \multicolumn{7}{|c|}{ Stock albino rat, 1914 series $F$. } \\
\hline \begin{tabular}{l|r} 
Control..... & 176 \\
Exercised.... & 182 \\
Per cent: Exerc.- \\
cont.
\end{tabular} & $\begin{array}{r}0.0557 \\
0.1145 \\
122.2500\end{array}$ & $\begin{array}{r}0.0076 \\
0.0058 \\
-42.4300\end{array}$ & $\begin{array}{r}0.0417 \\
0.0656 \\
47.7600\end{array}$ & $\begin{array}{r}0.0282 \\
0.0247 \\
-22.7400\end{array}$ & $\begin{array}{r}0.1931 \\
0.1836 \\
-4.2000\end{array}$ & $\begin{array}{l}3 \\
4\end{array}$ \\
\hline $\begin{array}{l}\text { Average percent- } \\
\text { age by which } \\
\text { exercised albino } \\
\text { rats differ from } \\
\text { control. Same } \\
\text { weight given to } \\
\text { each series }\end{array}$ & $\begin{array}{l}12.33(\mathrm{M} .) \\
84.33(\mathrm{~F} .)\end{array}$ & $\begin{array}{r}10.25 \text { (M.) } \\
-22.23(\mathrm{~F} .)\end{array}$ & $\begin{array}{l}0.84 \text { (M.) } \\
47.76(\mathrm{~F} .)\end{array}$ & -13.4400 & 4.8000 & \\
\hline
\end{tabular}


From the above it is clear that most of the ductless glands are subject to a considerable alteration as the result of exercise. Beyond pointing out that the exercised rats show, in the case of the testes, ovaries, hypophysis and suprarenals, relations similar to those found in the wild Norway, I am unable to give an interpretation of the changes observed. The data are therefore presented without further comment except to repeat that the alterations here noted are constant and are not the result of a great inherent variability of these organs.

\section{Alterations of central nervous system and of eyeballs}

Brain weight. On the average the brain weight of the exercised rat is 4.02 per cent heavier than that of the controls. This relatively greater weight of the exercised rat is true not only on the average, but also for all the series given in table 6 . A variation of 4 per cent is not usually regarded as a large figure, nevertheless it is certainly significant for this particular organ. Indeed, this gain of 4 per cent is the largest plus alteration so far obtained from our experiments. It seems safe to conclude from its constancy, as well as from relative uniformity of the value, that exercise increases the brain weight with respect to the body length. It should be noted also that the present results agree with the finding of Donaldson ('11) in this respect. It is not clear, however, whether this gain was due to a uniform enlargement of an entire mass, or to the increase of special divisions or structural components of the encephalon. A detailed analysis may settle this question in the future.

Spinal cord weight. The weight of the spinal cord evidently is not significantly altered. This is shown not only by its slight average modification of 0.88 per cent but also by the fact that the variation is not uniform in all the series. Donaldson found a difference of 0.65 per cent in favor of the control rat. All we can say about this part of the central nervous system is that exercise produces no significant alterations.

Amount of water in the brain and spinal cord. As shown in table 6 , the percentage of water in the brain and spinal cord is 
TABLE 6

Showing the weights of brain and spinal cord and of eyeballs of the exercised rats compared with those of the controls. Arrangement of data explained on $p .650$.

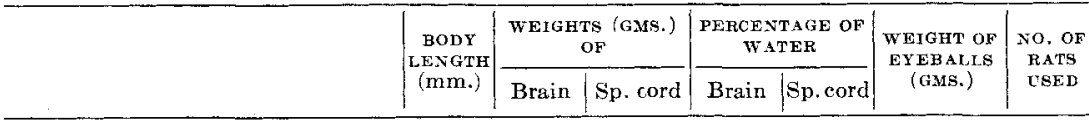

Stock albino rat (Donaldson' 11 ) $M$. and $F$.

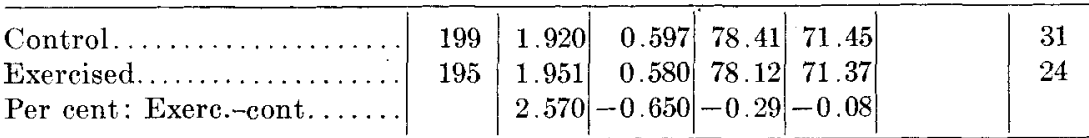

Stock albino rat, 1911 series $M$.

\begin{tabular}{|c|c|c|c|c|c|c|}
\hline Control. & 212 & 1.872 & 0.614 & 78.09 & 70.39 & 21 \\
\hline Exercised. & 195 & 1.866 & 0.564 & 78.08 & 71.05 & 11 \\
\hline Per cent: Exerc,-cont. & & 3.670 & 3.000 & -0.01 & 0.66 & \\
\hline
\end{tabular}

Inbred albino rat, 1912 series $M$.

\begin{tabular}{l|r|r|r|r|r|r|r}
\hline Control.................... & 212 & 1.784 & 0.610 & 78.57 & 71.40 & 0.294 & 9 \\
Exercised.............. & 214 & 1.868 & 0.603 & 78.40 & 71.20 & 0.299 & 10 \\
Per cent: Exerc.-cont. ..... & & 3.940 & -2.420 & -0.17 & -0.20 & 0 & \\
\hline
\end{tabular}

Inbred albino rat, 1912 series $F$

\begin{tabular}{l|r|r|r|r|r|r|r}
\hline Control................ & 191 & 1.715 & 0.547 & 78.24 & 70.89 & 0.288 & 6 \\
Exercised................ & 198 & 1.826 & 0.558 & 78.57 & 71.65 & 0.279 & 7 \\
Per cent. Exerc-cont..... & & 4.430 & -3.220 & 0.33 & 0.76 & -9.920 & \\
\hline
\end{tabular}

Stock albino rat, 1914 series $M$.

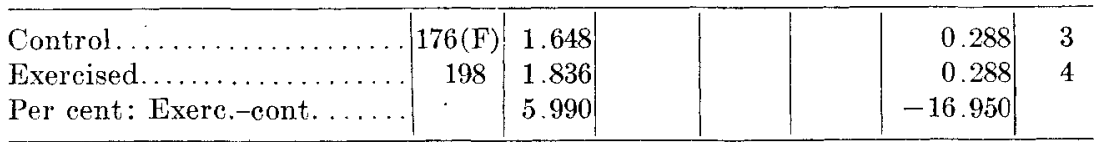

Stock albino rat, 1914 series $F$.

\begin{tabular}{|c|c|c|c|c|c|c|}
\hline 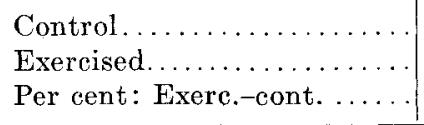 & $\begin{array}{l}176 \\
182\end{array}$ & $\begin{array}{l}1.648 \\
1.701 \\
2.060\end{array}$ & & & & $\begin{array}{r}0.288 \\
0.276 \\
-10.910\end{array}$ \\
\hline $\begin{array}{l}\text { Percentage by which exe } \\
\text { albino rats differ from con } \\
\text { Same weight given to each }\end{array}$ & & 4.020 & -0.88 & $|-0.02|$ & 0.41 & -9.45 \\
\hline
\end{tabular}


not modified. This result agrees with the findings of Donaldson ('11).

Eyeballs. As a sample of the sense organs, the eyeballs were examined. As will be seen from table 6 , the average weight of the eyeballs of the exercised rats is 9.45 per cent less than that of the non-exercised rat. The meaning of the smaller eyeballs in the exercised rats is not at all clear. I may mention, however, that from the data so far accumulated, the wild Norway rat has somewhat smaller eyeballs than the Albinos of the same body length.

THE EFFECT OF EXERCISE TAKEN FOR A PERIOD OF 30 DAYS

We have found that exercise taken for a period of 90 days produces changes in the organs to the same extent as exercise given for the period of 180 days (tables 3 to 6 ). It was thought interesting to determine the minimum period necessary to produce all the typical alterations. For this purpose the rats one month old were kept in the revolving cages for 30 days. The number of rats used was 6 controls and 6 experimented.

Without discussing the individual characters separately, we may make the following general statement.

(1) In no case are the alterations as large as those shown by the rats which had been kept in the revolving cages for the period of 90 or 180 days.

TABLE 7

Showing percentage values by which the several characters of the rats exercised for 30 days differ from those of the non-exercised. Males $=3$ controls and 4 exercised. Females $=9$ controls and 2 exercised. In this table only the final percentage values (i.e., for "\% exerc.-contr.") are given.

\begin{tabular}{|c|c|c|c|c|c|c|}
\hline & $\underset{\text { CENT }}{\text { PER }}$ & & PER CENT & & & $\begin{array}{c}\text { PER } \\
\text { CENT }\end{array}$ \\
\hline Tail length. & 0.4 & Heart & 8.0 & Thyroid & & 2.0 \\
\hline Body weight.... & 2.4 & Kidneys & 8.2 & Thymus & & -1.1 \\
\hline Brain. & 0.2 & Liver & -9.5 & Hypophysis & $\mathrm{M}$. & 25.7 \\
\hline Eyeballs. & 4.2 & Spleen & -52.9 & & 5 & 10.0 \\
\hline Alimentary tract. & -7.7 & Testes & 9.2 & Suprarenals & F. & $\begin{array}{r}8.0 \\
30.1\end{array}$ \\
\hline Lungs... & 4.7 & Ovaries & 51.4 & & & \\
\hline
\end{tabular}


(2) The amount of time necessary to produce the typical alterations varies according to different organs.

(3) While the heart and kidneys show a typical change, the liver shows a contrary modification. This may be due to a rapid utilization of reserve materials following a rapid growth, as well as the greater activity of the animal at this younger period.

(4) The early response of the sex glands to exercise may be the result of two combined factors; a greater supply of nutrition following the rapid circulation, and a strong tendency for growth of sex glands at this period of 50 to 60 days of age.

(5) Changes shown by other organs, particularly by the hypophysis, suprarenals and spleen, are very large. It is to be noted, however, that the weights of the hypophysis in the two sexes, despite the fact that both show a gain, tend to come together as in the 90 and 180 day series, while in the case of the suprarenals, the increase in the female is much the greater, a result again agreeing with the earlier series.

We may conclude from this short experiment that the effect of exercise is clearly shown in the rats which have been kept in the revolving cages for one month only, though the amount of modification varies considerably according to different organs.

TABLE 8

Showing the relation between heart weight and amount of exercise taken

\begin{tabular}{|c|c|c|c|c|}
\hline DESIGNATION OF RAT & $\begin{array}{c}\text { BODY LENGTH } \\
(\mathrm{mm})\end{array}$ & $\begin{array}{l}\text { HEART WEIGHT } \\
\text { (GMS.) }\end{array}$ & $\begin{array}{l}\text { No. OF MILES PER } \\
24 \text { IIOLRS }\end{array}$ & $\operatorname{SEX}$ \\
\hline $8 \mathrm{~B}_{10}$ & 222 & 0.725 & 0.4 & M. \\
\hline $7 A_{47}$ & 212 & 0.771 & 0.5 & M. \\
\hline $8 \mathrm{~B}_{9}$ & 215 & 0.799 & 0.6 & M. \\
\hline $7 \mathrm{~B}^{2}{ }_{16}$ & 218 & 0.853 & 0.6 & M. \\
\hline $7 \mathrm{~B}_{19}$ & 201 & 0.720 & 4.8 & M. \\
\hline $7 \mathrm{~B}_{48}$ & 220 & 0.888 & 6.5 & M. \\
\hline $6 \mathrm{~B}^{2}{ }_{82}$ & 217 & 1.149 & 6.7 & M. \\
\hline $7 A_{5}$ & 205 & 0.907 & 7.6 & M. \\
\hline $7 \mathrm{~A}_{4}$ & 212 & 0.915 & 7.6 & M. \\
\hline $7 \mathrm{~B}^{2}{ }_{17}$ & 198 & 0.745 & 6.2 & F. \\
\hline $7 \mathrm{~B}_{20}$ & 191 & 0.724 & 7.4 & F. \\
\hline $6 \mathrm{~B}^{2}{ }_{92}$ & 205 & 0.838 & 7.7 & F. \\
\hline $6 \mathrm{~B}^{2}{ }_{83}$ & 201 & 0.891 & 8.3 & F. \\
\hline $8 \mathrm{~B}_{11}$ & 197 & 0.762 & 10.2 & F. \\
\hline
\end{tabular}




\section{WEIGHT OF HEART IN RELATION TO THE AMOUNT OF EXERCISE TAKEN}

The variability in the activities of rats in the revolving cage suggested that there might exist a definite relation between the heart weight and the amount of exercise taken. To test this point table 8 was prepared. The data were taken from the 1912 series.

Among normal rats kept in the ordinary cages the correlation between heart weight and body length is very high (Hatai '13). Table 8 shows, however, that the correlation between the heart weight and body length in the exercised rats is almost zero, while, on the other hand, the correlation between the heart weight and amount of exercise taken is very high. To illustrate these points, I have divided the male records into three groups and the females into two groups according to the following plan:

$$
\begin{array}{lll}
\text { Male } & \text { Group 1 } & \text { Average for the first four sluggish rats } \\
& \text { Group 2 } & \text { Average for the rats which ran } 4.8 \text { to } 6.7 \text { miles } \\
\text { Group 3 } & \text { Average for the rats which ran } 7.6 \text { miles } \\
\text { Females } & \text { Group 1 } & \text { Average for the rats which ran } 6.2 \text { to } 7.7 \text { miles } \\
\text { Group 2 } & \text { Average for the rats which ran } 8.3 \text { to } 10.2 \text { miles }
\end{array}
$$

\begin{tabular}{|c|c|c|c|c|}
\hline \multirow{4}{*}{ Males. } & & $\begin{array}{l}\text { Body length } \\
\text { (mm.) }\end{array}$ & $\begin{array}{c}\text { Heart weight } \\
\text { (gms.) }\end{array}$ & $\begin{array}{c}\text { Mean distance } \\
\text { run } \\
\text { (miles) }\end{array}$ \\
\hline & Group 1 & 217 & 0.787 & 0.5 \\
\hline & Group 2 & 213 & 0.919 & 6.0 \\
\hline & Group 3 & 209 & 0.911 & 7.6 \\
\hline \multirow[t]{2}{*}{ Females. } & Group 1 & 198 & 0.769 & 7.1 \\
\hline & Group 2 & 199 & 0.827 & 9.3 \\
\hline
\end{tabular}

These average values are tabulated below.

From the above we notice that despite a greater body length in Group 1 (males) the corresponding heart weight is less in accordance with the least distance run. On the other hand, Group 3 (males) which has the least body length $(209 \mathrm{~mm}$.) gives almost as large a heart.weight as Group 2, whose body length is $213 \mathrm{~mm}$. In coincidence with this non-correlation 
between the body length and heart weight, we notice a harmonious relation between the heart weight and amount of exercise taken.

In the female series we notice that despite the practical identity in their body length, Group 2, which had run the greater distance, surpasses in heart weight Group 1, which had run the lesser distance. These facts indicate clearly that the heart increased in weight in relation to the amount of exercise taken, as was anticipated.

\section{GENERAL REMARKS}

It is clear from the foregoing that long-continued exercise (equivalent to a period of 7 to 14 years in man) in the albino rat produces many striking alterations in the organs. The modifications here given are found to be true not only for all the series, but in most cases even for the contrasted pairs of rats, and thus the results are not dependent on the variability of these organs. I am confident that the alterations are the result of the longcontinued exercise. It may not be out of place to mention here that a careful analysis of data has been made to see whether or not the infected lungs are in any way responsible for the changes observed in the organs. The results were negative.

The medical literature abounds with writings on the subject of 'exercise.' We find a universal recognition of hypertrophy of the heart following severe and long-continued exercise. I am not aware, however, that there are any similar statements concerning the modifications of other organs. Although from the results of physiological investigations on metabolism during or after severe physical exercise in man and in mammals, the occurrence of modifications in organs (such as the kidneys, liver, lungs, etc., besides the heart) are quite conceivable, yet we still lack the anatomical data for man.

From a purely biological standpoint, long-continued exercise has a special interest in the case of the domesticated albino rat. Former investigation has established the fact that the albino rat is a strain of the Norway rat (Hatai '07) and further, that these 
two forms of the rat possess central nervous systems of a dissimilar weight, the Norway having an absolutely heavier brain and spinal cord for a given boby weight (Donaldson and Hatai '11). Again, recently, I have shown that the relative weights of some of the ductless glands differ also in the Norway and albino rats (Hatai' $14 \mathrm{~b}$ ).

In rabbits, Darwin ('83) noted several physical differences, particularly in the cranial capacity between the wild and domesticated forms. The wild rabbits possessed a noticeably greater cranial capacity than the domesticated variety. More recently Lapicque and Girard ('07) have accumulated extensive data on the brain weights in wild and domesticated races. These two authors conclude also that the wild forms surpass the domesticated in their relative brain weights. Domestication, however, involves numerous interrelated factors which can be only slowly isolated by systematic study, and this experiment was devised to test the value of exercise, which seems to be one of the important factors forming the complex of domestication. The present investigation shows that at least in such organs as the brain, eyeballs, sex glands, hypophysis and suprarenals, the exercised Albinos show an approach to the Norway rat.

In conclusion, I may repeat that from the anatomical side the question of exercise is usually taken rather lightly in the case of man, nevertheless when we consider its striking effect on some of the organs of the rat, a further careful investigation of the subject, not only in the rat but in man also, seems certainly worth while, both from the general biological standpoint and for its bearing on hygiene.

\section{CONCLUSIONS}

1. The following determinations were made on exercised as compared with non-exercised rats: (1) External measurements; body and tail length and body weight. (2) Visceral organs; heart, kidneys, liver, lungs, spleen and alimentary tract. Ductless glands; testes, ovaries, hypophysis, suprarenals, thyroid 
and thymus. (4) Nervous system and sense organs; brain and spinal cord, and eyeballs.

2. The albino rats allowed to exercise in the revolving cages for 90 or 180 days show modifications in most of the organs. Among them, the following may be mentioned:

(a) The heart, kidneys and liver show an average excess of about 20 per cent, while the spleen shows a similar amount of deficiency.

(b) The brain weight shows an average excess of 4 per cent, while no change is noticed in the case of the spinal cord. (This result agrees with the observation of Donaldson '11).

(c) The ovaries give an excess of 84 per cent, while the testes give an excess of 12 per cent.

(d) The hypophysis, as well as the suprarenals, respond differently to exercise according to sex. Furthermore, these two organs show, as the result of exercise, an approach to the relations characteristic for the Norway rat.

(e) The exercised rats were either entirely free from lung infection or but slightly affected. The control rats, on the other hand, had badly infected lungs and in some series several of them were lost, presumably from the lung disease. Analysis of the data shows that the lung infection is not responsible for the changes observed in the organs.

3. Exercise for the period of 30 days showed in most organs modifications similar to those observed in rats exercised for 90 to 180 days.

4. In the exercised rats the heart weight and amount of exercise taken are highly correlated.

\section{LITERATURE CITED}

DARWIN, C. 1883 Variations of animals and plants under domestication. 2nd Ed. D. Appleton \& Co., vol. 1, p. 135.

Donaldson, H. H. 1911 On the influence of exercise on the weight of the central nervous system of the albino rat. Jour. Comp. Neur., vol. 21, pp. 129-137.

Donaldson, H. H., AND Hatai, S. 1911 A comparison of the Norway rat with the albino rat in respect to body length, brain weight, spinal cord weight and the percentage of water in both the brain and the spinal cord. Jour. Comp. Neur., vol. 21, pp. 417-458. 
Hatai, S. 1907 On the zoological position of the albino rat. Biol. Bull, vol. 12 , pp. 266-273.

1913 On the weights of the abdominal and the thoracic viscera, the sex glands, ductless glands and the eyeballs of the albino rat (Mus norvegicus albinus) according to body weight. Am. Jour. Anat., vol. 15, pp. 87-119.

1914 a On the weight of the thymus gland of the albino rat (Mus norvegicus albinus) according to age. Am. Jour. Anat., vol. 16, pp. 251-257.

$1914 \mathrm{~b}$ On the weight of some of the ductless glands of the Norway and of the albino rat according to sex and variety. Anat. Rec., vol. 8, pp. 511-523.

Lapicque, L., ANd Girard, P. 1907 Sur le poids de l'encephale chez les animaux domestiques. Compt. rend. Soc. de Biol., vol. 62, p. 1015.

Slonaker, J. R. 1908 Description of an apparatus for recording the activity of small mammals. Anat. Rec., vol. 2, pp. 116-121.

1912 The normal activity of the albino rat from birth to natural death, its rate of growth and the duration of life. Jour. Animal Behavior, vol. 2, pp. 20-42. 